\title{
Correction to: Employing Multivariate Statistics and Latent Variable Models to Identify and Quantify Complex Relationships in Typical Compression Studies
}

\author{
William C. Stagner, ${ }^{1}$ Abhay Jain, ${ }^{1}$ Antoine Al-Achi, ${ }^{1}$ and Rahul V. Haware ${ }^{1,2,3}$
}

Published online 2 August 2020

\section{Correction to: AAPS PharmSciTech.}

https://doi.org/10.1208/s12249-020-01712-1

During the transmission process in publishing the article online, the equal (=) sign was replaced with " 0 " in Equations 1 to 5 . The original article has been corrected.

Publisher's Note Springer Nature remains neutral with regard to jurisdictional claims in published maps and institutional affiliations.

William C. Stagner and Abhay Jain contributed equally to this work. The online version of the original article can be found at https:// doi.org/10.1208/s12249-020-01712-1

\footnotetext{
${ }^{1}$ Campbell University College of Pharmacy \& Health Sciences, Buies Creek, NC 27506, USA.

${ }^{2}$ Division of Pharmaceutics Sciences, Arnold \& Marie Schwartz College of Pharmacy and Health Sciences, The Long Island University, Brooklyn, NY 11201-5497, USA.

${ }^{3}$ To whom correspondence should be addressed. (e-mail: baughmanm@aaps.org)
} 